\title{
Strategi Promosi Produk Kerajinan Daur Ulang Sampah Untuk Menarik Minat Beli Masyarakat di Bank Sampah Sri Rejeki
}

\author{
Habibah $^{\mathrm{a}, 1}$, Afridayani ${ }^{\mathrm{b}, 2}$, Lyandra Aisyah Margie $^{\mathrm{c}, 3}$, Fitria Anggraini Rostianti $^{\mathrm{d}, 4}$ \\ a,b,c,dProdi S1 Akuntansi, Fakultas Ekonomi, Universitas Pamulang* \\ * habibahrh233@gmail.com
}

\begin{abstract}
Abstrak
Pengabdian kepada masyarakat ini memiliki tujuan umum untuk membantu mitra mengatur strategi promosi produk kerajinan daur ulang sampah sehingga menarik minat beli masyarakat, strategi promosi yang tepat akan sangat membantu mitra dalam memasarkan hasil kerajinan. Tema PKM ini adalah Strategi Promosi, dengan melibatkan para pengajar dan narasumber Dosen-dosen Program Studi Akuntansi dari Universitas Pamulang. Hasil Pelaksanaan PKM yang dilakukan pada tanggal 18, 19 dan 20 Juni 2020 adalah menambah ilmu di bidang pemasaran, terutama tentang strategi promosi dari para peserta kelompok Pengurus Bank Sampah Sri Rezeki di Benda Baru, Tangerang Selatan, Banten. Respon para peserta sangat baik dan senang karena sangat terbantu dalam pembelajaran tentang strategi promosi. Saran yang disampaikan adalah kegiatan PKM kedepannya agar dilakukan berkesinambungan sehingga, para peserta senantiasa mendapatkan bimbingan dalam melakukan strategi promosi sehingga produk hasil kerajinan dapat menarik minat beli masyarakat. Kepada masyarakat agar semakin antusias dalam mengumpulkan sampah karena bisa memberikan nilai ekonomis tinggi.
\end{abstract}

Kata kunci: Strsategi Promosi, Minat Beli Masyarakat

\begin{abstract}
This community service has a general goal to help partners set a strategy for promoting waste recycling handicraft products so as to attract public buying interest, an appropriate promotional strategy will greatly assist partners in marketing handicraft products. The theme of this PKM is Promotion Strategy, by involving lecturers and resource persons Lecturers in the Accounting Study Program from Pamulang University. The results of the PKM implementation carried out on 18, 19 and 20 June 2020 were adding knowledge in the field of marketing, especially about promotion strategies from the participants of the Sri Rezeki Waste Bank Management group in Benda Baru, South Tangerang, Banten. The response of the participants was very good and happy because it was very helpful in learning about the promotion strategy. The suggestion that was conveyed was the PKM activities in the future to be carried out continuously so that the participants would always get guidance in conducting promotional strategies so that handicraft products could attract people's buying interest. To the community to be more enthusiastic in collecting waste because it can provide high economic value.
\end{abstract}

Keywords: Promotion Structure, Public Buying Interest 


\section{PENDAHULUAN}

Salah satu permasalahan yang sampai saat ini masih dihadapi di semua kota di Indonesia termasuk kota Tangerang Selatan adalah sampah. Permasalahan ini muncul di perkotaan karena keterbatasan lahan pekarangan yang dimiliki masyarakat kota, sehingga mereka tidak dapat mengelola sampah rumah tangganya sendiri.

Upaya penanggulangan sampah dilakukan dengan berbagai hal, antara lain program bank sampah. Bank sampah merupakan kegiatan yang bersifat mengajarkan mayarakat untuk memilah sampah serta menumbuhkan kesadaran masyarakat dalam pengelolaan sampah secara bijak. Masyarakat diajarkan bagaimana memilah sampah organik dan non-organik sebelum disetorkan ke bank sampah (Rosharlianti, Z., 2020)

Bank sampah yang menerapkan konsep 3R (Reuse, Reduce, dan Recycle) sangat efektif karena ada keterlibatan warga secara aktif dimana warga bisa langsung memilah sampah yang ada (Benarda, B., 2020). Sampah yang tadinya tidak bernilai bisa Bank sampah sebagai suatu program pengelolaan lingkungnan yang dirancang oleh pemerintah sesuai dengan Peraturan Menteri Negara Lingkungan Hidup Republik Indonesia Nomor 13 tahun 2012 Pasal ayat 1 dan 2 menjelaskan bahwa kegiatan Reduse, Reuse, dan Recycle, atau disebut dengan kegiatan 3R adalah mengumpulkan, memilah, menggunakan kembali.

Produk kerajinan hasil olahan sampah dapat bernilai ekonomi, bahkan dapat bersaing baik di pasar nasional maupun internasional. Maka dari itu setiap penghasil produk harus mempunyai strategi promosi untuk menarik konsumen dan mempunyai minat untuk memanfaatkan produk tersebut. Dalam hal ini dengan memperkenalkan produk dari segi manfaat tidak hanya dapat digunakan juga guna menjaga lingkungan dari sampah-sampah dan harus dapat menampilkan hasil produksinya yang dapat memberikan sugesti kepada konsumen yaitu dengan adanya kualitas produk yang dimilikinya.

Dengan adanya promosi maka informasi mengenai produk mudah untuk diketahui oleh calon konsumen, sehingga diharapkan penjualan akan meningkat dan perusahaan akan mencapai target omzet yang telah ditentukan. Berdasarkan hasil observasi awal, Bank Sampah Sri Rejeki merupakan salah satu usaha inovasi kreatif peduli lingkungan yang ada Jl. Borobudur 1 C 26 No 5 RT 01 RW 04 Serua Permai, Benda Baru Pamulang, Tangerang Selatan, dengan pemanfaatan sampah sebagai bahan dasar pembuatan produk kerajinan. Secara ekonomi Bank Sampah Sri Rejeki cukup membantu para masyarakat dari sisi perekonomian. Promosi ini dapat dilakukan secara online, 
dan memiliki keunggulan misalnya kenyamanan, memiliki akses 24 jam sehari, efisiensi alternative ruang, jangkauan wilayah yang tidak terbatas (Syarifudin, S., 2020).

Masyarakat menjual sampahnya kepada Bank Sampah kemudian diberikan semacam tabungan (rekening) untuk menyimpan hasil penjualannya dalam bentuk tabungan lebaran dan sebagainya. Sampah yang tadinya tidak memiliki nilai jual, setelah diolah menjadi barang bernilai ekonomi tinggi, misalnya menjadi, tas, keranjang, dompet, tempat tisu, gantungan kunci dan berbagai kerajinan lainnya. Sementara untuk sampah organik yang diolah menjadi pupuk, diprioritaskan untuk digunakan oleh warga bersangkutan untuk bercocok tanam.

Seiring berjalannya waktu dan semakin berkembanganya Bank Sampah Sri Rejeki maka otomatis jumlah sampah yang telah ditabung nasabah semakin meningkat dan menumpuk di gudang Bank Sampah Sri Rejeki, akan tetapi produk kerajinan hasil daur ulang sampah masih belum sepenuhnya diserap pasar, karna masih minimnya minat masyarakat untuk membeli produk kerajinan dari daur ulang sampah ini. Untuk memperkuat daya jangkau pemasaran, entitas dalam hal ini Bank Sampah juga perlu bergabung dengan beberapa komunitas yang memiliki jenis usaha yang sama, karena dengan begitu akan mendapatkan informasi seputar usaha yang dijalani (Handijono, A., 2020).

Metode

(PKM) ini diselenggarakan pada hari Kamis sampai Sabtu pada tanggal 18 sampai 20 Juni 2020, bertempat di Bank Sampah Sri rezeki Benda Baru, Pamulang, Tangerang Selatan, dengan peserta yaitu pengelola dan anggota Bank Sampah.

Teknis yang digunakan dalam melakukan pengabdian sebagai berikut:

1. Metode yang akan dilakukan pada kegiatan pengabdian adalah melakukan penyuluhan/ pelatihan dalam membekali mitra bagaimana caranya melakukan promosi secara offline maupan online.

2 Melakukan pendampingan dalam hal membuat konten online yang menarik untuk kegiatan promosi.

3 Kegiatan PKM ini dilakukan daring atau online dengan menggunakan aplikasi online untuk membantu mitra dalam melakukan kegiatan promosi. Bentuk PKM online ini menggunakan aplikasi Zoom Meeting.

Jenis kegiatan Pengabdian Kepada Masyarakat (PKM) yang akan diselenggarakan adalah mengenai pelatihan tentang strategi promosi sehingga menarik minat beli masyarakat terhadap hasil kerajinan yang berasal dari sampah. 
Tujuan dan sasaran yang ingin dicapai dalam kegiatan ini adalah sebagai berikut:

1. Peserta dapat menganalisis strategi promosi produk kerajinan daur ulang sampah untuk menarik minat beli masyarakat di Bank Sampah Sri Rejeki

2. Peserta mengetahui kendala dan upaya yang dihadapi Bank Sampah Sri Rejeki mempromosikan produk kerajinan daur ulang sampah.

\section{HASIL DAN PEMBAHASAN}

Kegiatan promosi yang dilakukan Bank Sampah untuk menginformasikan produk kerajinan daur ulang sampah sehingga produknya lebih dikenal dan menarik minat beli masyarakat antara lain:

a. Periklanan (Adverstising) Bank Sampah menggunakan periklanan yaitu melalui:

1. Media brosur, dengan cara menyebarkan brosur ke masyarakat.

2. Menggunakan mobile branding dengan berkerja sama dengan Pemda.

3. Media internet yaitu mempromosikan produk kerajinan daur ulang sampah melalui facebook dan website.

b. Promosi Penjualan (Sales Promotion) promosi penjualan yaitu:

1. Memberikan potongan harga (discount) bagi konsumen yang membeli produk kerajinan secara borongan.

2. Mengadakan pameran agar masyarakat mengetahui produk kerajinan daur ulang sampah

c. Personal Selling Bank Sampah melakukan promosi dengan personal selling melalui sosilisasi ke desa-desa agar masyarakat mengetahui produk kerjinan daur ulang sampah.

d. The Power of Word of Mouth (Mulut ke Mulut) Bank Sampah melakukan promosi menggunakan promosi dari mulut ke mulut (Word of Mout) dimulai dengan para pengerus serta anggota dengan sering mengunakan produk produk daur ulang sampah dan menceritakan pengalamannya kepada orang-orang terdekat seperti sahabat, anggota keluarga dan kerabat lainnya.

\section{KESIMPULAN DAN SARAN}

Para Pengurus serta anggota Bank sampah dapat melakukan kegiatan promosi yang lebih intensif dimasa Pandemi Covid-19 ataupun di masa depan. Dengan cara melakukan periklanan, Promosi penjualan dan The Power of Word of Mouth (Mulut ke Mulut) sehingga produk hasil daur ulang 
sampah lebih dikenal masyarakat dan terus mengembangkan produk-produk daur ulang sampah serta pemberbanyak jenis-jenis

\section{REFERENSI}

Benarda, B., Oktavianna, R., Sari, S., Saputri, S. W., \& Septiowati, R. (2020). MENABUNG SAMPAH UNTUK MASA DEPAN PADA BANK SAMPAH PAPRIKA GRAHA INDAH PAMULANG. ABDIMISI, 1(2), 104-112

Handijono, A., Gunarto, R. I., Dewi, E. K., Marpitasa, S., \& Kwartarani, Y. (2020). MEMAJUKAN UKM CONFETTI DENGAN MEMANFAATKAN TEKNOLOGI DIGITAL. ABDIMISI, 1(2), 119-127.

Marisa (2018) Strategi promosi produk produknya.

kerajinan daur ulang sampah untuk menarik minat beli masyarakat di bank sampah NTB Mandiri lingkungan Banjar Selaparang, Ampenan Kota Mataram. Undergraduate thesis, Universitas Islam Negeri Mataram

Rosharlianti, Z., Anisa, A., Setyawati, W., Nurbaeti, N., \& Akhsani, N. (2020). PELATIHAN AKUNTANSI PADA PENGELOLAAN BANK SAMPAH "MENGUBAH SAMPAH MENJADI RUPIAH". ABDIMISI, 1(2), 82-88.

Syarifudin, S., Nugroho, A. R., Yuwono, A. S., Suripto, S., \& Asmedi, S. (2020). Strategi Naikan Omzet Lewat Online. Abdimisi, 1(2), 113-118. 